\title{
Cytogenetics of bisexual/unisexual species of Poecilia. VI. Additional nucleolus organizer region chromosomal clones of Poecilia formosa (Amazon molly) from Texas, with a survey of chromosomal clones detected in the Amazon molly
}

\author{
LUCIANA SOLA*†, PEDRO M. GALETTI JR $\ddagger$, PAUL J. MONACO§ \& ELLEN M. \\ RASCH§ \\ †Department of Animal and Human Biology, University of Rome 1, Via A. Borelli 50, 00161 Rome, Italy, \\ ‡Departamento de Genética e Evolução, Universidade Federal de São Carlos, via Washington Luis, Km 235, Caixa \\ Postal 676, 13565-905 Säo Carlos, SP, Brazil and §Department of Anatomy and Cell Biology, James H. Quillen \\ College of Medicine, East Tennessee State University, Johnson City, TN 37614-0421, U.S.A.
}

\begin{abstract}
This study reports the results of different staining techniques on the chromosomes of two Poecilia formosa lineages, providing evidence of two additional nucleolus organizer region (NOR) chromosomal clones in this gynogenetic fish. A comparative analysis of chromosomal clones detected in the Amazon molly, along with their frequency and distribution in different collecting sites, is also presented, and clonal heterogeneity resulting from chromosome changes is discussed.
\end{abstract}

Keywords: clonal heterogeneity, cytogenetics, Poecilia formosa, unisexual fish.

\section{Introduction}

Poecilia formosa, the Amazon molly, is a diploid unisexual species of hybrid origin reproducing by gynogenesis. Sperm from a related bisexual species is needed to initiate development of eggs, but inheritance is strictly maternal and genotypes are replicated from one generation to the next in a clonal manner by functional apomixis (Rasch et al., 1982). The only detectable changes expected would be caused by mutation or somatic crossing-over. Clonal diversity in $P$. formosa complexes has been reported by tissue graft analysis (Kallman 1962), biochemical techniques and mating experiments (Balsano et al. 1989), ribosomal gene analysis (Monaco et al. 1988) and DNA fingerprinting (Turner et al. 1990). Chromosomal evidence for clonal differences has also been previously suggested (Sola et al. 1992a, 1993b; Galetti and Rasch 1993a).

\footnotetext{
*Correspondence: E-mail: sola@axrma.uniroma1.it.
}

This report presents the results of C-banding, silver $(\mathrm{Ag})$ and fluorescent staining with chromomycin $\mathrm{A}_{3}\left(\mathrm{CMA}_{3}\right)$ on the chromosomes of two $P$. formosa lineages, providing evidence for two additional NOR chromosomal clones. A survey of the chromosomal clones detected in the Amazon molly (Sola et al. 1992a, 1993b; Galetti \& Rasch 1993a) is also presented. In previous papers, references to the precise field collection sites were missing and, so far, a comparative chromosome classification has not been attempted. This survey provides idiograms that allowed us to summarize the number and type of the chromosomal clones detected, along with their frequency and distribution in the different collecting sites. Considering that cytogenetic data have recently shown a higher resolution than DNA fingerprinting data (Schartl et al. 1995) in detecting genetic exchanges between bisexual and unisexual species, the state of the art on $P$. formosa chromosomal clones may be useful for future observations on the evolutionary dynamics of such a peculiar species. 


\section{Materials and methods}

Specimens from two different laboratory-reared lineages of $P$. formosa were analysed. Progenitor females were originally taken from the San Marcos River, Texas (SMC lineage) and from the Rio Grande drainage in Brownsville, Texas (RRV lineage). Table 1 summarizes field sampling data for all $P$. formosa specimens presently and previously investi- gated for NORs, including those from the Rio Soto la Marina drainage (Sola et al. 1992a, 1993b; Galetti \& Rasch 1993a). Somatic metaphases were silver stained to identify active NORs and $\mathrm{CMA}_{3}$ stained to detect both active and inactive NORs in the chromosome complement. C-banding was performed to localize heterochromatin. All staining techniques were carried out as described previously (Galetti \& Rasch 1993a, b).

Table 1 Field sampling data for Poecilia formosa

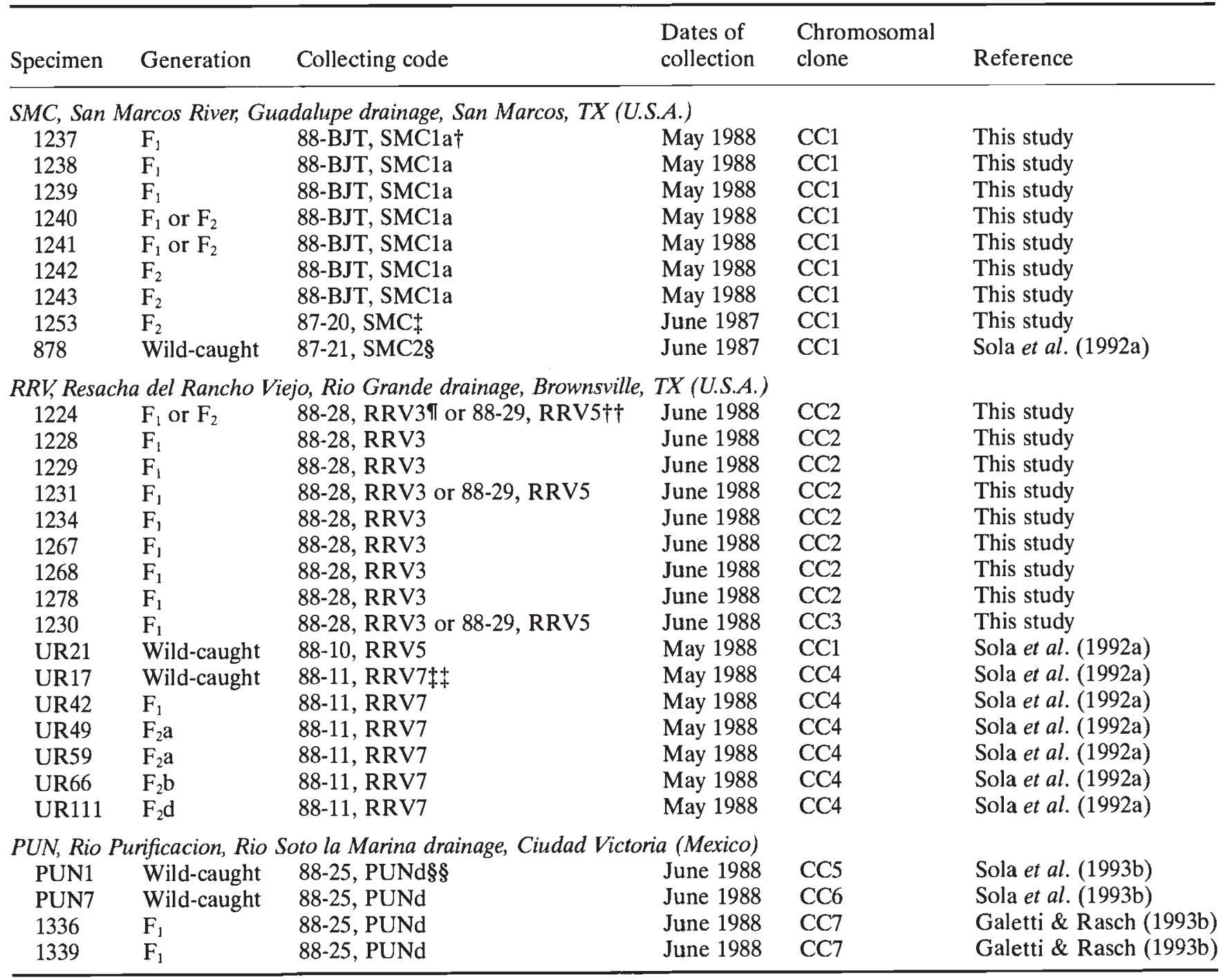

†SMC1a, Cade's Cove, Guadelupe River.

$\ddagger$ SMC1, about $0.5 \mathrm{~km}$ upstream from Cape's Camp.

$\S S M C 2$, Hyacinth Pool, about $0.25 \mathrm{~km}$ upstream from Cape's Camp.

IRRV3, near Olmito, Old State Fish Hatchery.

ł‡RV5, near Olmito, about $3.2 \mathrm{~km}$ west of US 77 on TX 732 .

¥\$RRV7, San Benito, junction of highways US 77 and TX 732 .

$\S \S$ PUNd, highway 101 at Nuevo Padilla, about $1.2 \mathrm{~km}$ from the bridge. 


\section{Results}

To compare the present data with those previously obtained on $P$. formosa specimens from the same (Sola et al. 1992a) or different drainages (Galetti \& Rasch 1993a; Sola et al. 1993b), idiograms were drawn (Fig. 1) pursuing a parsimonious criterion, i.e. to minimize the arbitrariness in classification, NOR-bearing chromosomes showing both similar size and NOR location were considered to be homologous. According to the hybrid origin of the species, in the idiograms the members of each chromosome pair were represented as being of different size.
Poecilia formosa specimens from both lineages showed the 46 subtelocentric, acrocentric karyotype typical of the species. All SMC individuals showed up to two Ag-NORs and two $\mathrm{CMA}_{3}$-positive sites (Table 2). Silver and $\mathrm{CMA}_{3}$ staining (Fig. 2) identified NOR locations on the short arms of chromosome 1a as well as on the short arms of a large-sized chromosome, numbered 4. Similar NOR numbers and locations were observed in a specimen from San Marcos analysed previously (Sola et al. 1992a) (Table 1). Thus, based upon the analysis of nine specimens from the San Marcos area, one NOR chromosomal clone has been detected. This clone was named chromosomal clone 1, CC1 (Fig. 1a). a

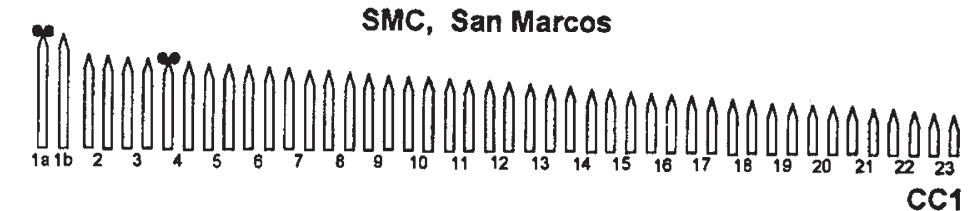

b

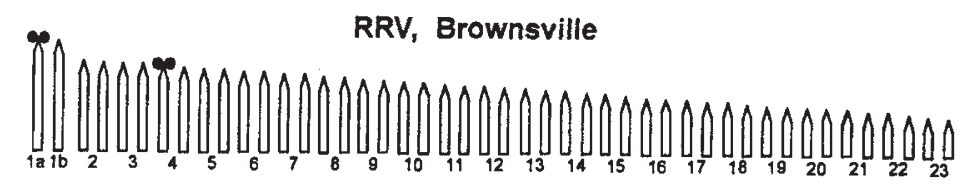

CC1

c

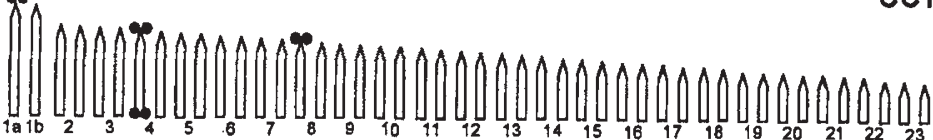

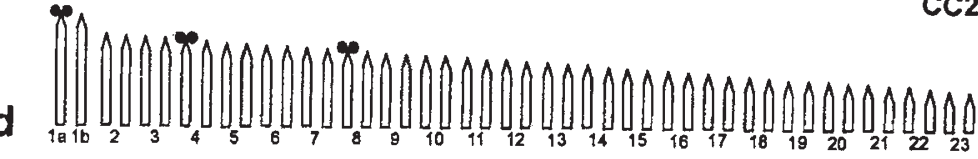

CC3

e

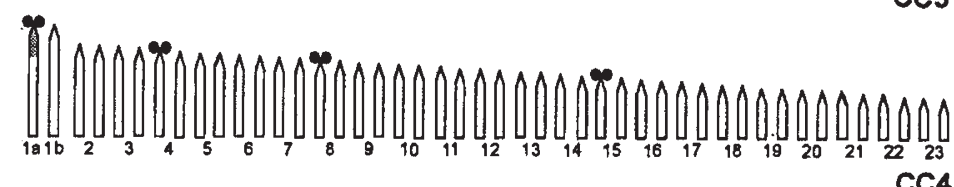

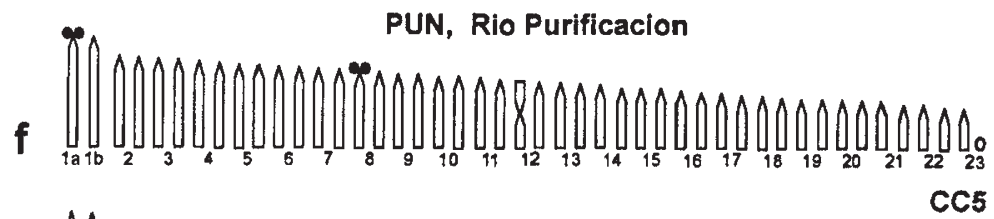

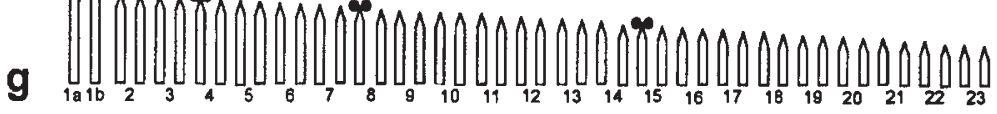

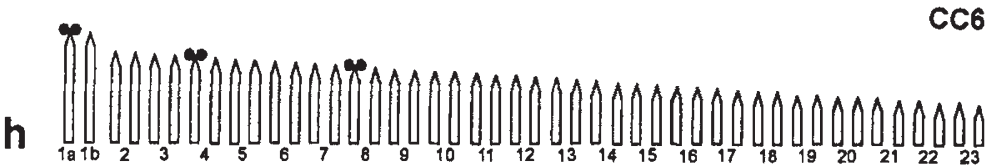

$\mathrm{CC7}$
Fig. 1 Idiograms representing chromosomal clones, $\mathrm{CC} 1$ to $\mathrm{CC} 7$, detected in Poecilia formosa. •, NOR locations. 
Table 2 Ag-NORs and $\mathrm{CMA}_{3}$-positive sites in Poecilia formosa

\begin{tabular}{|c|c|c|c|c|c|c|c|c|c|}
\hline \multirow[b]{2}{*}{ Animal } & \multirow[b]{2}{*}{$2 n=46$} & \multicolumn{4}{|c|}{ Ag-NORs } & \multicolumn{4}{|c|}{$\mathrm{CMA}_{3}{ }^{+}$sites } \\
\hline & & 1 & 2 & 3 & 4 & 1 & 2 & 3 & 4 \\
\hline \multicolumn{10}{|c|}{ SMC, San Marcos } \\
\hline 1237 & 31 & 2 & 12 & - & - & - & 11 & - & 一 \\
\hline 1238 & 18 & - & 6 & - & - & - & 10 & - & - \\
\hline 1239 & 15 & - & 3 & - & - & - & 5 & - & - \\
\hline 1240 & 25 & 2 & 8 & - & - & - & 6 & - & - \\
\hline 1241 & 29 & 1 & 5 & - & - & - & 14 & - & - \\
\hline 1242 & 26 & - & 4 & - & - & - & 15 & - & - \\
\hline 1243 & 11 & - & 2 & - & - & - & 5 & - & - \\
\hline 1253 & 33 & 1 & 10 & - & - & - & 11 & - & - \\
\hline Total & 188 & 6 & 50 & - & - & - & 77 & - & - \\
\hline \multicolumn{10}{|c|}{ RRV, Brownsville } \\
\hline 1224 & 45 & - & - & 1 & 11 & - & - & - & 15 \\
\hline 1228 & 24 & - & - & - & 8 & - & - & - & 6 \\
\hline 1229 & 14 & - & - & 1 & 7 & - & - & - & 10 \\
\hline 1230 & 32 & - & 9 & 3 & - & - & - & 8 & - \\
\hline 1231 & 21 & - & - & 2 & 3 & - & - & - & 6 \\
\hline 1234 & 16 & - & - & 2 & 2 & - & - & - & 7 \\
\hline 1267 & 14 & - & - & - & 4 & - & - & - & 15 \\
\hline 1268 & 18 & - & - & 2 & 6 & - & - & - & 10 \\
\hline 1278 & 9 & - & - & 1 & 3 & - & - & - & 5 \\
\hline Total & 193 & - & 9 & 12 & 44 & - & - & 8 & 74 \\
\hline
\end{tabular}

Fig. 2 (a) Ag- and (b) $\mathrm{CMA}_{3}$-stained metaphases of the SMC lineage of Poecilia formosa. Arrows indicate NORs.

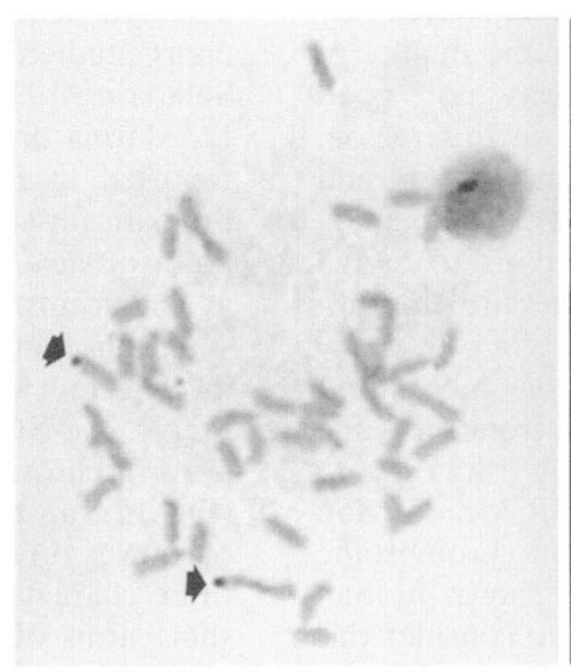

a

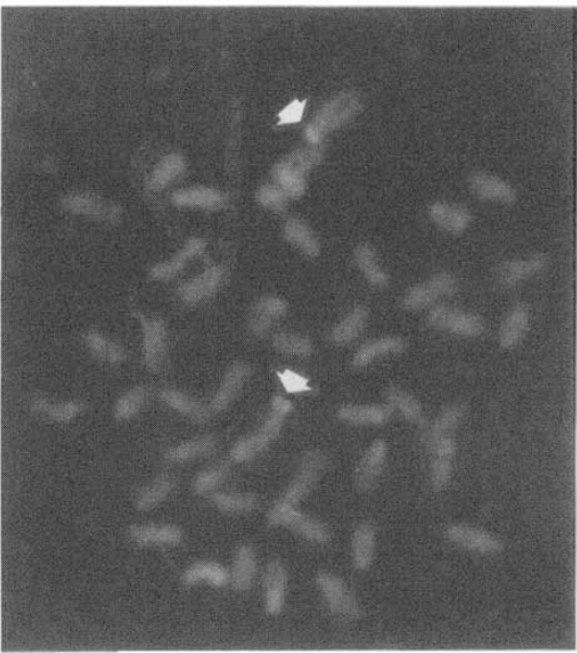

b
The RRV lineage individuals showed up to four Ag-NORs, with the exception of specimen 1230, which had a maximum of three Ag-NORs; correspondingly, eight specimens showed four $\mathrm{CMA}_{3}$-positive sites and specimen 1230 showed three (Table 2).
The four NORs were localized on three heterologous chromosomes (Fig. 3a, b), as summarized in Fig. 1c: on the short arms of chromosome 1a, on the short arms and on the telomeric region of the long arms of one homologue 4 and on the short arms of 


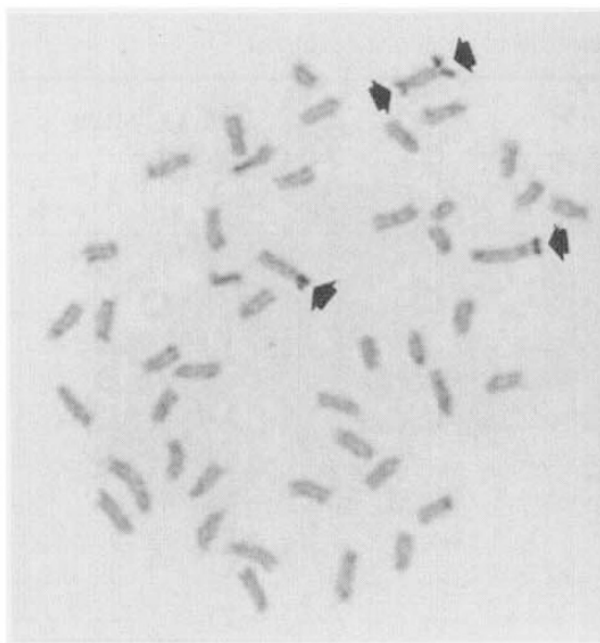

a

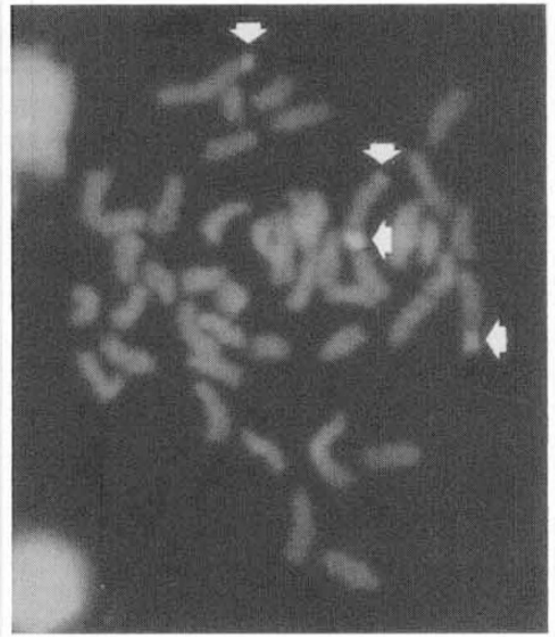

b

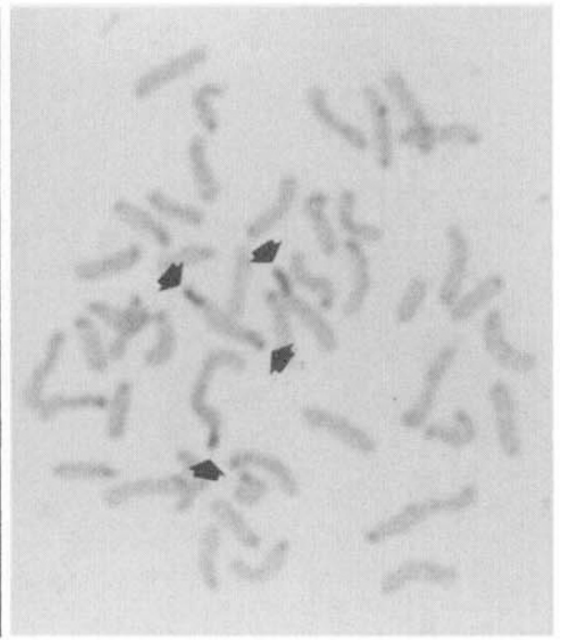

C

Fig. 3 (a) Ag-, (b) $\mathrm{CMA}_{3}$-stained and (c) C-banded metaphases of the RRV lineage of Poecilia formosa. Arrows indicate the C-positive NORs.

one member of pair 8. All NORs were found to be C-positive, including the telomeric one (Fig. 3c). This clone was named CC2 (Fig. 1c).

In specimen 1230 , a telomeric signal on the long arms of homologue 4 was not evident after silver or $\mathrm{CMA}_{3}$ staining (data not shown); this could be caused either by a smaller, undetectable, NOR or by its absence in this specimen. Even if the quality of metaphases from this specimen was not good enough to distinguish smaller NORs in this region, the clear-cut difference in the frequency of $\mathrm{Ag}$ - and $\mathrm{CMA}_{3}$-positive sites between this and the remaining RRV specimens (Table 2) prompted us to assign specimen 1230 tentatively to a different chromosomal clone, CC3 (Fig. 1d).

Seven individuals, wild-caught or laboratoryreared $F_{1}$ or $F_{2}$ generations (Table 1) from the same area, have been analysed previously (Sola et al. 1992a). Specimen UR21 showed NOR locations on the short arms of chromosome 1a and chromosome 4 (Fig. 1b), i.e. the same pattern as shown by San Marcos specimens; thus, we propose to consider this specimen as a component of CC1 (see also Discussion). The remaining six RRV specimens showed a NOR pattern different from those so far described: four NORs located on the short arms of chromosome 1a and three large and medium-sized chromosomes. Thus, these specimens can be ascribed to a different clone, CC4 (Fig. 1e). This clone is also characterized by the presence of a subcentromeric $\mathrm{CMA}_{3}$-positive C-band on the long arm of chromosome 1a. In the RRV area, therefore, four chromo- somal clones have been detected from the analysis of 16 specimens (Table 1 ). These clones are identifiable because of different numbers of NORs - two, three or four - or, in the case of equal numbers of NORs (four) because of their different locations.

To complete the picture of chromosomal clones detected in the Amazon molly, idiograms of specimens studied previously (Galetti \& Rasch 1993a; Sola et al. 1993b) from Rio Purificacion in the Soto La Marina drainage, north-eastern Mexico, are also reported in Fig. 1(f-h). CC5 (Fig. 1f) is the most dramatically different clone from a chromosomal point of view. It is characterized by the presence of a metacentric and a microchromosome in a 46-chromosome complement. In the only specimen investigated with such a chromosome complement, PUN1, Ag-NORs have been detected on the short arms of chromosome 1a and chromosome 8. In CC6 (Fig. 1g), up to four Ag-NORs have been observed, but never on chromosome 1 . Thus, this clone seems to be characterized by the absence of NORs on the short arms of chromosome 1a. This claim is made cautiously, as this specimen was analysed by silver staining only. However, NORs of chromosome 1a were found to be silver-stained, i.e. active, in a very high percentage of cells in all $P$. formosa specimens analysed - almost 100 per cent of silver-stained metaphase plates in this report and in specimens from the same area analysed previously (Galetti \& Rasch 1993a), and in more than 85 per cent of the cells in specimens from San Marcos and Brownsville (Sola et al. 1992a). As far as CC7 (Fig. 1h) is 
concerned, specimens show similar NOR numbers and locations to clone $\mathrm{CC} 3$ in Brownsville. In this case, however, we did not use the most parsimonious hypothesis, considering the geographically disjunct origin of the specimens and the improbability of the mixing of animals between these localities. Therefore, from the analysis of four specimens, three distinct chromosomal clones have been identified in the Rio Purificacion area.

\section{Discussion}

In this study, two new NOR chromosomal clones, named $\mathrm{CC} 2$ and $\mathrm{CC} 3$, were detected by $\mathrm{Ag}$ and $\mathrm{CMA}_{3}$ staining and C-banding in $P$. formosa specimens from Brownsville. As far as the comparative analysis of present and previous data (Sola et al. 1992, 1993b; Galetti \& Rasch 1993a) is concerned, it should be emphasized that, in $P$. formosa, as well as in all the other fish species investigated in this manner, the single chromosomes could not be identified with certainty, as chromosomes do not show the banding patterns observed in higher vertebrates (Bernardi 1993). However, the parsimonious criterion we used allows us to state that at least seven chromosomal clones have been identified by the analysis of 29 specimens from three different drainages (Table 1). Moreover, in the San Marcos area, the same NOR chromosomal clone, $\mathrm{CC} 1$, has probably been detected in specimens collected in different years (Table 1).

Generally, when clonal divergences exist within unisexual organisms of hybrid origin, there are two possible interpretations: either multiple hybridization events or changes subsequent to the origin of unisexual species have occurred. Recent studies of mitochondrial DNA support the notion of a few hybridization events involving closely related females in the origin of unisexual $P$. formosa (Avise et al. 1992). On the other hand, clonal diversity in the Amazon molly, shown several times by histocompatibility and biochemical methods (Kallman 1962; Balsano et al. 1989; Turner et al. 1990; among others), was found to be much higher than originally thought.

Analysing the chromosomal clones identified, it is important to note that populations of fish from the Guadalupe and Rio Grande drainages share a common origin. Indeed, $P$. formos $a$ is not native to the San Marcos area, and Hubbs (1964) reported that 'about 16 Amazon mollies were accidentally released from the San Marcos State Fish Hatchery into the San Marcos River in 1955. These fish had been obtained at the Lula B. Sams State Fish Hatchery in Olmito, Texas.' This is the reason that we considered specimen UR21 from Brownsville to belong to $\mathrm{CC} 1$, detected within San Marcos specimens. Although specimen UR21 (collecting code RRV5) did not come directly from the Lula B. Sams State Fish Hatchery, all of these sites from Brownsville are overflow ditches that could drain into the Resacha de Rancho Viejo. Thus, although populations of fish from the two drainages have been disjunct for 40 years, this chromosome clone would have remained unchanged during this period. According to expectations, the colonized area (Guadalupe drainage, nine specimens, one clone) has a lower clonal diversity than the founder populations (Rio Grande drainage, 16 specimens, four clones).

Our results appear to be consistent with histocompatibility studies that have shown that at least three clones of unisexual $P$. formosa exist in Brownsville, and that specimens of $P$. formosa from San Marcos belong to two of the most common Brownsville clones (Kallman 1962; Balsano et al. 1989). However, contrasting results were obtained by DNA fingerprinting (Turner et al. 1990). Samples from the two drainages show no overlap in clonal composition, and more clones are present in the San Marcos sample (13 specimens, six clones) than in that of the supposed founder population from Lulu Sams (eight specimens, three clones). These data are particularly striking because at least some of the specimens from San Marcos analysed here came from the same field collection as those studied by Turner et al. (1990).

Whichever technique was used, high clonal heterogeneity was revealed in $P$. formosa specimens from the Rio Soto la Marina drainage. Histocompatibility and allozymic analyses have shown the highest clonal diversity in this drainage, especially at Nuevo Padilla (Balsano et al. 1989). A sample of 19 specimens from this same station contained 16 clones when analysed by DNA fingerprinting (Turner et al. 1990). Three clones were detected from chromosome analysis of four specimens from this same field collection (Sola et al. 1993b). It is worth noting that in this part of the $P$. formosa range significant proportions of poeciliid populations are composed of unisexual triploids, which apparently result from failure of sperm exclusion during reproduction of the Amazon molly (Rasch \& Balsano 1989). Allozymic observations suggest that triploids are the most evolutionarily dynamic part of the breeding complex (Turner et al. 1983). Cytogenetic observations (Sola et al. 1993b) also point to the probability of genetic exchanges between diploid and triploid 
individuals. All of the data indicate that in this area genetic changes of evolutionary significance are occurring between unisexual-bisexual species of Poecilia.

On the whole, it seems unlikely that such a high degree of chromosomal clonal diversity could depend upon multiple hybridization events. It is more likely that such clonal diversity would depend on mutations and changes subsequent to the origin of unisexual species. Considering the nature of NORs - repetitive genes associated to spacers made of repetitive DNA - it is no wonder that they can easily change and rapidly propagate in a unisexual population, owing to its gynogenetic mode of reproduction, which allows that particular cytomorph to amplify. Moreover, intraclonal polymorphism in ribosomal DNA between successive generations of one lineage has been detected (Monaco et al. 1988). NORs have also been shown to be quite polymorphic in every Poecilia species studied so far, including the putative parental species of the $P$. formosa (Sola et al. 1990, 1992a,b, 1993a,b; Galetti \& Rasch 1993a,b), so that no simple phylogenetic relationship can be evoked. The adaptive value, if any, of the high clonal heterogeneity depending on changes of NORs, as well as on changes of stretches of simple DNA sequences, detected by DNA fingerprinting, cannot easily be understood.

On the other hand, chromosome changes, such as those detected in CC5 from Rio Purificacion, are likely to represent events of adaptive and evolutionary relevance. Recent data from Schartl et al. (1995), showing that microchromosomes in unusually pigmented $P$. formosa offspring represent incorporation of subgenomic amounts of paternal DNA, point in this direction.

\section{Acknowledgements}

Field work in Mexico was made possible by collecting permit 1746 issued by the Direccion General de Regulacion Pesquera, Instituto National de Pesca, for which we are sincerely grateful. We thank $\mathrm{Dr}$ Joseph Balsano for his invaluable help in making field collections in Mexico in 1988 and Dr Bruce J. Turner for providing some of the specimens used. The technical assistance of Ms Deborah Lee is gratefully and especially acknowledged. Supported in part by grants MURST and CNR to L.S., by National Science Foundation Grant DEB 77-03257 to E.M.R and by grants from the Whitehall Foundation to E.M.R. and P.J.M.

\section{References}

AVISE, J. C., TREXLER, J. C., TRAVIS, J. AND NELSON, W. S. 1991. Poecilia mexicana is the recent female parent of the unisexual fish $P$. formosa. Evolution, 45, 1530-1533.

BALSANO, J. S., RASCH, E. M. AND MONACO, P. J. 1989. The evolutionary ecology of Poecilia formosa and its triploid associate. In: Meffe, G. K. and Snelson, F. F. (eds) Ecology and Evolution of Livebearing Fishes, pp. 227-298. Prentice Hall, Englewood Cliffs, NJ.

BERNARD1, G. 1993. Genome organization and species formation in vertebrates. J. Mol. Evol., 37, 331-337.

GALETTI, P. M., JR. AND RASCH, E. M. 1993a. NOR variability in diploid and triploid forms of Poecilia formosa as shown by silver nitrate and chromomycin $\mathrm{A}_{3}$ staining. Brazil. J. Genet., 16, 927-938.

GALETT1, P. M., JR. AND RASCH, E. M. 1993b. Chromosome studies in Poecilia latipunctata with NOR polymorphism as shown by silver nitrate and chromomycin $A_{3}$ (Teleostei: Poeciliidae). Ichthyol. Explor. Freshwaters, 4, 269-277.

HuBss, c. 1964. Interactions between a bisexual fish species and its gynogenetic sexual parasite. Bull. Texas Mem. Mus., 8, 1-72.

KALLMAN, K. D. 1962. Population genetics of a gynogenetic teleost, Mollienesia formosa (Girard). Evolution, 16, 497-504.

MONACO, P. J., RASCH, E. M. AND MUSICH, P. R. 1988. Polymorphisms in ribosomal DNA of a unisexual fish. Copeia, 1988, 774-777.

RASCH, E. M. AND BALSANO, J. S. 1989. Trihybrids related to the unisexual molly fish, Poecilia formosa. In: Dawley, R. M. and Bogart, J. P. (eds) Evolution and Ecology of Unisexual Vertebrates, Bulletin 466, pp. 252-267. New York State Museum, Albany.

RASCH, E. M., MONACO, P. J. AND BALSANO, J. S. 1982. Cytophotometric and autoradiographic evidence for functional apomixis in a gynogenetic fish, Poecilia formosa, and its related, triploid unisexuals. Histochemistry, 73, 515-533.

SCHARTL, M., NANDA, I., SCHLUPP, I., WILDE, B., EPPLEN, J. T., SCHMID, M. AND PARZEFALL, J, 1995. Incorporation of subgenomic amounts of DNA as compensation for mutational load in a gynogenetic fish. Nature, 373, $68-71$.

SOLA, L., MONACO, P. J. AND RASCH, E. M. 1990. Cytogenetics of bisexual/unisexual Poecilia. I. C-bands, AgNOR polymorphisms and sex chromosomes in three populations of Poecilia latipinna. Cytogenet. Cell Genet., 53, 148-154.

SOLA, L., IASELL1, V., ROSSI, A. R., RASCH, E. M. AND MONACO, P. J. 1992a. Cytogenetics of bisexual/unisexual species of Poecilia. III. The karyotype of Poecilia formosa, a gynogenetic species of hybrid origin. Cytogenet. Cell Genet., 60, 236-240.

SOLA, L., ROSSI, A. R., IASELLI, V., RASCH, E. M. AND MONACO, P. J. 1992b. Cytogenetics of bisexual/unisexual species of Poecilia. II. Analysis of heterochromatin and nucleolar organizer regions in Poecilia mexicana mexi- 
cana by C-banding and DAPI, quinacrine, chromomycin $\mathrm{A}_{3}$, and silver staining. Cytogenet. Cell Genet., 60, 229-235.

SOla, L., BRESSANEllo, S., RASCH, E. M. AND MONACO, P. J. 1993a. Cytogenetics of bisexual/unisexual species of Poecilia. IV. Sex chromosomes, sex chromatin composition and Ag-NOR polymorphisms in Poecilia latipinna: a population from Mexico. Heredity, 70, 67-71.

SOLA, L., ROSSI, A. R., BRESSANELLO, S., RASCH, E. M. AND MONACO, P. J. 1993b. Cytogenetics of bisexual/unisexual species of Poecilia. V. Unisexual poeciliids with anom- alous karyotypes from northeastern Mexico. Cytogenet. Cell Genet., 63, 189-191.

TURNER, B. J., BAISANO, J. S., MONACO, P. J. AND RASCH, E. M. 1983. Clonal diversity and evolutionary dynamics in a diploid-triploid breeding complex of unisexual fishes (Poecilia). Evolution, 37, 798-809.

TURNER, B. J., ELDER, J. F., JR., LAUGHLIN, T. F. AND DAVIS, w. P. 1990. Genetic variation in clonal vertebrates detected by simple-sequence DNA fingerprinting. Proc. Natl. Acad. Sci. U.S.A., 87, 5653-5657. 